\title{
Surface effects on saturation magnetization in nanoporous $\mathrm{Ni}$
}

\section{$\operatorname{AUTHOR}(\mathrm{S})$ :}

Hakamada, Masataka; Takahashi, Masaki;

Furukawa, Toshiyuki; Mabuchi, Mamoru

\section{CITATION:}

Hakamada, Masataka ...[et al]. Surface effects on saturation

magnetization in nanoporous Ni. Philosophical Magazine 2010, 90 (14): 1915-1924

ISSUE DATE:

2010-05-14

URL:

http://hdl.handle.net/2433/237668

\section{RIGHT:}

This is an Accepted Manuscript of an article published by Taylor \& Francis in 'Philosophical Magazine' on 2010, available online: https://www.tandfonline.com/10.1080/14786430903571461; The full-text file will be made open to the public on 14 May 2011 in accordance with publisher's 'Terms and Conditions for Self-Archiving'.; This is not the published version. Please cite only the published version.; この論文は出版社版でありません。引用の際には出版社版をご確認ご利用くだ 


\title{
Surface effects on saturation magnetization in nanoporous $\mathrm{Ni}$
}

\author{
Masataka Hakamada $^{\mathrm{a} *}$, Masaki Takahashi ${ }^{\mathrm{b}}$, Toshiyuki Furukawab and \\ Mamoru Mabuchi ${ }^{\mathrm{b}}$
}

${ }^{a}$ Materials Research Institute for Sustainable Development, National Institute of Advanced Industrial Science and Technology, 2266-98 Anagahora, Shimo-shidami, Moriyama, Nagoya 463-8560, Japan

${ }^{b}$ Department of Energy Science and Technology, Graduate School of Energy Science, Kyoto University, Yoshidahonmachi, Sakyo, Kyoto 606-8501, Japan

*Corresponding author. E-mail: masataka-hakamada@aist.go.jp

\begin{abstract}
Nanoporous Ni specimens with the ligament lengths of 10-210 nm and the specific surface areas of $0.03-0.58 \mathrm{~nm}^{-1}$ were fabricated by the dealloying of $\mathrm{Ni}_{0.25} \mathrm{Mn}_{0.75}$ alloy and annealing at $473-873 \mathrm{~K}$, and their saturation magnetizations were investigated in terms of their size dependence. Saturation magnetization decreased with decreasing ligament length or increasing specific surface area. This trend is the same as that for nanoparticle $\mathrm{Ni}$. However, the saturation magnetization of nanoporous $\mathrm{Ni}$ tends to be lower than that of the nanoparticle $\mathrm{Ni}$ when their specific surface areas are the same. It is therefore suggested that the surface effect due to a noncollinear arrangement is enhanced by the surface defects in the nanoporous $\mathrm{Ni}$.
\end{abstract}

Keywords: nanoporous; nickel; magnetic materials

\section{Introduction}

Nanosized materials exhibit unique electronic, optical, magnetic, chemical and mechanical properties that are greatly different from those of bulk materials. It is known that nanoparticles [1-5] and nanocrystallines [6,7] exhibit superparamagnetism or a very low coercivity because their coercivity strongly depends on the six power of diameter or grain size [4,6,7]. In addition, the nanosized materials often show a lower saturation magnetization than their corresponding bulk materials [4,8-10]. This has been explained by core-shell models [10,11], in which the nanosized materials consist of ferromagnetically aligned core spins and an inactive surface layer. Liu and Zhang [4] estimated the thickness of the inactive layer as $0.45 \mathrm{~nm}$. Fonseca et al. [5] showed that Ni nanoparticles have no oxide layer. Hence, the inactive layer is attributed to the noncollinear magnetism at the surfaces $[2,12]$. The surface effect plays a critical role in the magnetization of the nanosized 
materials. Recently, unique surface effects have been reported in coated nanosized materials [13-15].

Various nanoporous metals, namely, Au [16-18], Ag [17,18], Cu [17,19], Ni [17,20], Sn [21], Ta [22], Ti [23] and Pt [17,24,25] have been developed. These metals exhibited remarkable properties, such as the ideal high strength [26,27], surface-enhanced Raman scattering [28], high catalytic ability [29], wide-range $\mathrm{H}_{2}$ sensing [30] and electrical conductivity controlled by the surface charge [31]. Sun et al. [32] demonstrated that nanoporous Ni exhibits a higher coercivity and a lower saturation magnetization than bulk Ni. Recently, it was found from an investigation of annealed nanoporous $\mathrm{Ni}$ [33] that its coercivity decreases with decreasing ligament length in a range below the critical size of about $50 \mathrm{~nm}$. This trend for the nanoporous $\mathrm{Ni}$ is the same as those for the nanoparticle and nanocrystalline $\mathrm{Ni}$; however, the size dependence of coercivity for the nanoporous $\mathrm{Ni}$ was lower than those for the other materials because the dimension of exchange length in the ligament was 1-2 for the nanoporous $\mathrm{Ni}$, resulting in the low size dependence of coercivity [33]. Thus, the size dependence of coercivity for the nanoporous $\mathrm{Ni}$ has been investigated in detail. On the other hand, the size dependence of saturation magnetization in nanoporous $\mathrm{Ni}$ has not been understood sufficiently thus far.

The ligament length of nanoporous metals can be varied by post processing treatments, such as annealing and immersion in an acid solution [34,35]. In this study, nanoporous Ni specimens with the ligament lengths of 10-210 nm are fabricated by the dealloying of $\mathrm{Ni}_{0.25} \mathrm{Mn}_{0.75}$ alloy and annealing at $473-873 \mathrm{~K}$, and saturation magnetization is investigated in terms of its size dependence. 


\section{Experimental}

Commercially available $\mathrm{Ni}$ (> 99.9\%) and Mn (> 99.9\%) ingots were melted together by arc melting under an $\mathrm{Ar}$ atmosphere to produce a precursor $\mathrm{Ni}_{0.25} \mathrm{Mn}_{0.75}$ alloy ingot. The Ni0.25Mn0.75 ingot was water-quenched after the homogenization annealing at $1173 \mathrm{~K}$ for $24 \mathrm{~h}$ to avoid the formation of Ni-Mn intermetallics. During the waterquenching, the minimal surface oxidation of the $\mathrm{Ni}_{0.25} \mathrm{Mn}_{0.75}$ ingot was inevitable. Formed oxides on the surface of $\mathrm{Ni}_{0.25} \mathrm{Mn}_{0.75}$ ingot was removed by grinding. Nanoporous Ni was fabricated by the selective electrolytic dealloying of the Ni-Mn alloy. A three-electrode electrochemical cell controlled by a potentiostat was used for dealloying. Dealloying was carried out at room temperature using a platinum electrode as a counter electrode and $1 \mathrm{~mol} / \mathrm{L}\left(\mathrm{NH}_{4}\right)_{2} \mathrm{SO}_{4}$ as an electrolyte. The alloy ingot was held at an applied electrochemical potential of $-650 \mathrm{mV}$ (versus a saturated calomel electrode) for about $24 \mathrm{~h}$ until no current was detected.

A transmission electron micrograph of as-processed nanoporous $\mathrm{Ni}$ is shown in Fig. 1. It can be seen that the pore sizes or ligament lengths are of the nanometer order. The selected area electron diffraction pattern (inset in Fig. 1) shows the monocrystalline nature of the viewed part in the micrograph. As-processed nanoporous Ni specimens were annealed at $473-873 \mathrm{~K}$ for $15 \mathrm{~min}$ in an inert gas to vary the ligament length, and the ligament length and specific surface area of each specimen were measured by image analyses.

Microstructures of the nanoporous Ni specimens were investigated by X-ray diffraction (XRD) with a $\mathrm{Cu} \mathrm{K} \alpha$ radiation $(\lambda=0.15418 \mathrm{~nm})$, scanning electron microscopy (SEM) and transmission electron microscopy (TEM). Also, energydispersive X-ray (EDX) analysis was carried out by SEM with an EDX device. Magnetization hysteresis loops were recorded at room temperature using a vibrating 
sample magnetometer, and the saturation magnetization of the nanoporous $\mathrm{Ni}$ was investigated in terms of its size dependence.

\section{Results and discussion}

Scanning electron micrographs of the nanoporous Ni specimens are shown in Fig. 2. The image analyses showed that the ligament length and specific surface area are 10 $\mathrm{nm}$ and $0.34 \mathrm{~nm}^{-1}$ for the as-processed specimen, $11 \mathrm{~nm}$ and $0.30 \mathrm{~nm}^{-1}$ for the specimen annealed at $473 \mathrm{~K}, 18 \mathrm{~nm}$ and $0.19 \mathrm{~nm}^{-1}$ for the specimen annealed at 573 $\mathrm{K}, 33 \mathrm{~nm}$ and $0.10 \mathrm{~nm}^{-1}$ for the specimen annealed at $673 \mathrm{~K}, 79 \mathrm{~nm}$ and $0.045 \mathrm{~nm}^{-1}$ for the specimen annealed at $773 \mathrm{~K}$, and $210 \mathrm{~nm}$ and $0.020 \mathrm{~nm}^{-1}$ for the specimen annealed at $873 \mathrm{~K}$, respectively. There were minor differences in porous characteristics between the as-processed specimen and the specimen annealed at 473 $\mathrm{K}$, indicating that diffusion at $473 \mathrm{~K}$ insufficiently coarsened the ligament length.

The XRD patterns of the as-processed and annealed specimens are shown in Figs. 3 (a) and (b). Three characteristic peaks for metallic Ni $\left(2 \theta=44.5^{\circ}, 51.8^{\circ}\right.$ and $76.4^{\circ}$ ) were observed in all the XRD patterns, but there were no peaks for the Mn phases and compounds containing Mn. This indicates that obtained nanoporous specimens shown in Figs. 1 and 2 are essentially metallic Ni. The peaks were sharper for specimens annealed at higher temperatures. Inspection of the XRD patterns (Fig. 3 (b)) reveals that the as-processed specimen had lower 111 peak diffraction angle than the specimen annealed at $473 \mathrm{~K}$. Therefore, it is suggested that the annealing at $473 \mathrm{~K}$ cannot increase the ligament size, but can relax the lattice structure, although the quantitative evaluation is difficult because of the peak broadening.

Figure 4 shows the magnetization curves of the nanoporous Ni specimens. Magnetization hysteresis loops are typical of ferromagnetic materials. The saturation 
magnetization of the nanoporous Ni decreased with decreasing ligament length. The relationship between the saturation magnetization and the ligament length is summarized in Fig. 5 (a). It is known that the saturation magnetization decreases with decreasing nanoparticle size $[4,8,9]$. Thus, the size dependence of saturation magnetization for the nanoporous $\mathrm{Ni}$ is seemingly the same as that for the nanoparticles.

To evaluate the surface effect on the saturation magnetization of the nanoporous $\mathrm{Ni}$, the variation in saturation magnetization as a function of specific surface area for the nanoporous Ni is shown in Fig. 5 (b). For reference, the saturation magnetization [2] of the nanoparticle $\mathrm{Ni}$ is superimposed in Fig. 5 (b). Note that the saturation magnetization remained almost constant (approximately $57 \mathrm{emu} / \mathrm{g}$ ) in a range below the specific surface area of $0.18 \mathrm{~nm}^{-1}$, but it significantly decreased above the critical value of specific surface area. The critical value of the specific surface area of $0.18 \mathrm{~nm}^{-1}$ corresponds to the ligament length of $33 \mathrm{~nm}$. For ferrite nanoparticles [8], the saturation magnetization gradually decreased with decreasing size in a particle diameter range of $15-50 \mathrm{~nm}$, but it sharply decreased below $15 \mathrm{~nm}$. On the other hand, the nanocrystalline Ni showed the minor grain size dependence of the saturation magnetization [36,37]. Thus, the magnetic properties of the nanoporous $\mathrm{Ni}$ are in agreement with those of the nanoparticles, but not with those of the nanocrystalline $\mathrm{Ni}$.

It is of interest to note that the saturation magnetization above the critical value of ligament size (and below the critical value of specific surface area) for the nanoporous $\mathrm{Ni}(57 \mathrm{emu} / \mathrm{g}$ ) is larger than that of bulk $\mathrm{Ni}$ (55 emu/g) [14]. This may be related to the chemical compositions or surface effects. Figure 6 shows the EDX analytical result for the as-processed nanoporous Ni specimen. Quantitative analyses 
from EDX results showed that the Mn content was approximately 5 atomic \%. It can be seen from Figs 2 and 6 that $\mathrm{Mn}$ atoms are dissolved in $\mathrm{Ni}$. The magnetic properties of $\mathrm{Ni}-\mathrm{Mn}$ alloys strongly depend on the $\mathrm{Ni} / \mathrm{Mn}$ ratio, and the magnetization is enhanced by low Mn concentrations [38]. Therefore, it is likely that the larger saturation magnetization of the nanoporous $\mathrm{Ni}$ is attributed to the solid solution of $\mathrm{Mn}$ in $\mathrm{Ni}$, not to the surface effects inherent to the nanoporous $\mathrm{Ni}$.

The trend for the decrease in saturation magnetization below the critical size in the nanoporous $\mathrm{Ni}$ is the same as that in the nanoparticles, as mentioned previously. The energy of a magnetic particle is proportional to its size or volume via the number of magnetic molecules in a single magnetic domain. When this energy becomes comparable to the thermal energy, the thermal fluctuation significantly reduces the total magnetic moment. Hence, the magnetization of nanoparticles is often much lower than that of the corresponding bulk because an individual nanoparticle becomes a single magnetic domain. However, the nanoporous Ni specimens had a much larger volume than a single nanoparticle. Therefore, it is suggested that the thermal fluctuation is not responsible for the decrease in magnetization for the nanoporous Ni. Other factors that contribute to the decrease in magnetization are the presence of disorder structures, such as amorphous phases and grain boundaries. In the nanoporous Ni specimens, however, there are no amorphous phases and the grain size is not of the nanometer order, and therefore, the decrease is not due to the disorder structures.

It has been reported that the nanoparticles exhibit ferromagnetism, although the corresponding bulks exhibit paramagnetism or antimagnetism; that is, the surface of the nanoparticles is ferromagnetic despite the nonferromagnetism of the inside $[39,40]$. The surface ferromagnetism is due to the distinct surface density of states 
near the Fermi level for the paramagnetic state [41]. On the other hand, the ferromagnetic nanoparticles exhibit a lower saturation magnetization than the corresponding bulks [4,8,9]. Lizárraga et al. [42] pointed out that even typical ferromagnetic materials, such as $\mathrm{Ni}$, can possibly be stabilized in a noncollinear magnetic order under special environments. The spin states at the surfaces of the nanoparticles are greatly different from those of the inside. Hence, the decrease in the magnetization of the nanoporous $\mathrm{Ni}$ is due to the noncollinear arrangement at its surface.

Figure 5 (b) also reveals that the saturation magnetization of the nanoporous $\mathrm{Ni}$ tends to be lower than that of the nanoparticle Ni when the specific surface area of the former is equal to that of the latter, suggesting that the surface effect due to the noncollinear magnetic order is enhanced in the nanoporous Ni compared with that in the nanoparticle Ni. In addition, it is worthwhile to note that the saturation magnetization of the as-processed specimen was lower than that of the specimen annealed at $473 \mathrm{~K}$, although the specific surface area of the former $\left(0.58 \mathrm{~nm}^{-1}\right)$ was almost the same as that of the latter $\left(0.55 \mathrm{~nm}^{-1}\right)$. This suggests that the as-processed specimen has a larger noncollinear arrangement than the annealed specimen. Noncollinear magnetism depends on the presence of surface defects [43]. Also, a variation in lattice or bond distance induces the unique magnetism of the nanosized materials $[44,45]$. The as-processed nanoporous Ni specimen has many surface defects at the surfaces and a high residual strain, resulting from the selective electrochemical dealloying of a more active component in a homogeneous alloy. These features are responsible for the enhancement of noncollinear magnetism in the as-processed nanoporous Ni specimen. However, surface and bulk reorganization is induced by annealing [46], which is also seen in the present work (Fig. 3 (b)). 
Therefore, a reduction in noncollinear arrangement in the annealed specimen may be due to the reorganization or relaxation induced by annealing.

The difference in saturation magnetizations between as-processed and 473-Kannealed samples may be also caused by the homogenization of residual Mn via diffusion during the annealing; nevertheless, the effect of surface noncollinear arrangement in nanoporous $\mathrm{Ni}$ is important because the line (dashed line in the Fig. 5 (b)) extrapolated from the plots of the 473-, 573- and 673-K-annealed samples which seem to have homogeneous Mn distribution due to annealing, comes under the plot of nanoparticle Ni.

\section{Conclusions}

Nanoporous Ni specimens with different ligament lengths or specific surface areas were fabricated by the dealloying of $\mathrm{Ni}_{0.25} \mathrm{Mn}_{0.75}$ alloy and annealing, and their saturation magnetizations were investigated in terms of their size dependence.

Saturation magnetization remained almost constant in a range below a specific surface area of $0.18 \mathrm{~nm}^{-1}$, but it significantly decreased above the critical value of specific surface area. The saturation magnetization below the critical value of specific surface area was larger than that of bulk Ni. This is likely to be related to the solid solution of $\mathrm{Mn}$ in Ni. The sharp decrease in saturation magnetization above the critical value of specific surface area may be due to the noncollinear arrangement at the surfaces. It is suggested that the surface effect due to the noncollinear arrangement is enhanced by the surface defects in nanoporous $\mathrm{Ni}$, when compared to that in nanoparticle $\mathrm{Ni}$.

\section{References}

[1] C. Estournés, T. Lutz, J. Happich, T. Quaranta, P. Wissler and J. L. Guille, J. Magn. Magn. Mater. 173 (1997) p. 83. 
[2] D.-H. Chen and S.-H. Wu, Chem. Mater. 12 (2000) p. 1354.

[3] S. I. Woods, J. R. Kirtley, S. Sun and R. H. Koch, Phys. Rev. Lett. 87 (2001) No. 137205.

[4] C. Liu and Z. J. Zhang, Chem. Mater. 13 (2001) p. 2092.

[5] F. C. Fonseca, G. F. Goya, R. F. Jardim, R. Muccillo, N. L. V. Carreño, E. Longo and E. R. Leite, Phys. Rev. B 66 (2002) No. 104406.

[6] G. Herzer, Scr. Metall. Mater. 33 (1995) p. 1741.

[7] E. Kita, N. Tsukuhara, H. Sato, K. Ota, H. Yanagihara, H. Tanimoto and N. Ikeda, Appl. Phys. Lett. 88 (2006) No. 152501.

[8] T. Sato, T. Iijima, M. Seki and N. Inagaki, J. Magn. Magn. Mater. 65 (1987) p. 252.

[9] W. Gong, H. Li, Z. Zhao and J. Chen, J. Appl. Phys. 69 (1991) p. 5119.

[10] S. Gubbala, H. Nathani, K. Koizol and R. D. K. Misra, Physica B 348 (2004) p. 317.

[11] C. Caizer, J. Magn. Magn. Mater. 251 (2002) p. 304.

[12] K. V. P. M. Shafi, A. Gedanken, R. Prozorov and J. Balogh, Chem. Mater. 10 (1998) p. 3445.

[13] D. A. van Leeuwen, J. M. van Ruitenbeek, L. J. de Jongh, A. Ceriotti, G. Pacchioni, O. D. Häberlen and N. Rösch, Phys. Rev. Lett. 73 (1994) p. 1432.

[14] J.-H. Hwang, V. P. Dravid, M. H. Teng, J. J. Host, B. R. Elliott, D. L. Johnson and T. O. Mason, J. Mater. Res. 12 (1997) p. 1076.

[15] T. Bala, S. D. Bhame, P. A. Joy, B. L. V. Prasad and M. Sastry, J. Mater. Chem. 14 (2004) p. 2941.

[16] J. Erlebacher, M. J. Aziz, A. Karma, N. Dimitrov and K. Sieradzki, Nature (London) 410 (2001) p. 450.

[17] P. Jiang, J. Cizeron, J. F. Bertone and V. L. Colvin: J. Am. Chem. Soc. 121 (1999) p. 7957.

[18] D. Walsh, L. Arcelli, T. Ikoma, J. Tanaka and S. Mann, Nat. Mater. 2 (2003) p. 386.

[19] D. V. Pugh, A. Dursun and S. G. Corcoran, J. Mater. Res. 18 (2003) p. 216.

[20] J. Rösler, O. Näth, S. Jäger, F. Schmitz and D. Mukherji, Acta Mater. 53 (2005) p. 1397.

[21] A. H. Whitehead, J. M. Elliott, J. R. Owen and G. S. Attard, Chem. Commun. (1999) p. 331.

[22] H. El-Sayed, S. Singh, M. T. Greiner and P. Kruse, Nano Lett. 6 (2006) p. 2995.

[23] J. Jayaraj, B. J. Park, D. H. Kim, W. T. Kim and E. Fleury, Scr. Mater. 55 (2006) p. 1063.

[24] G. S. Attard, P. N. Bartlett, N. R. B. Coleman, J. M. Elliott, J. R. Owen and J. H. Wang, Science 278 (1997) p. 838.

[25] H. Liu, P. He, Z. Li and J. Li, Nanotechnology 17 (2006) p. 2167.

[26] J. Biener, A. M. Hodge, A. V. Hamza, L. M. Hsiung and J. H. Satcher, Jr., J. Appl. Phys. 97 (2005) No. 024301.

[27] M. Hakamada and M. Mabuchi, Scr. Mater. 56 (2007) p. 1003.

[28] S. O. Kucheyev, J. R. Hayes, J. Biener, T. Huser, C. E. Talley and A. V. Hamza, Appl. Phys. Lett. 89 (2006) No. 053102.

[29] V. Zielasek, B. Jürgens, C. Schulz, J. Biener, M. M. Biener, A. V. Hamza and M. Bäumer, Angew. Chem.-Int. Edit. 45 (2006) p. 8241.

[30] D. Ding and Z. Chen, Adv. Mater. 19 (2007) p. 1996.

[31] A. K. Mishra, C. Bansal and H. Hahn, J. Appl. Phys. 103 (2008) No. 094308.

[32] L. Sun, C.-L. Chien and P. C. Searson, Chem. Mater. 16 (2004) p. 3125. 
[33] M. Hakamada, M. Takahashi, T. Furukawa and M. Mabuchi, Appl. Phys. Lett. 94 (2009) No. 153105.

[34] R. Li and K. Sieradzki, Phys. Rev. Lett. 68 (1992) p. 1168.

[35] M. Hakamada and M. Mabuchi, Nano Lett. 6 (2006) p. 882.

[36] M. J. Aus, B. Szpunar, A. M. El-Sherik, U. Erb, G. Palumbo and K. T. Aust, Scr. Metall. Mater. 27 (1992) p. 1639.

[37] Y. Sasaki, M. Hyakkai, E. Kita, H. Tanimoto and A. Tasaki, Nanostruct. Mater. 12 (1999) p. 907.

[38] A. Stephen, T. Nagarajan and M. V. Ananth, Mater. Sci. Eng. B 55 (1998) p. 184.

[39] H. Hori, T. Teranishi, Y. Nakae, Y. Seino, M. Miyake and S. Yamada: Phys. Lett. A 263 (1999) p. 406.

[40] T. Shinohara, T. Sato and T. Taniyama, Phys. Rev. Lett. 91 (2003) No. 197201.

[41] C. L. Fu and A. J. Freeman, Phys. Rev. B 33 (1986) p. 1755.

[42] R. Lizárraga, L. Nordström, L. Bergqvist, A. Bergman, E. Sjöstedt, P. Mohn and O. Eriksson, Phys. Rev. Lett. 93 (2004) No. 107205.

[43] N. S. Yartseva, S. V. Yartsev and J. C. Parlebas, Surf. Sci. 602 (2008) p. 3388.

[44] Y. T. Jeon, J. Y. Moon, G. H. Lee, J. Park and Y. Chang, J. Phys. Chem. B 110 (2006) p. 1187.

[45] Y. T. Jeon and G. H. Lee, J. Appl. Phys. 103 (2008) No. 094313.

[46] Y. Wang, S. Teitel and C. Dellago, Nano Lett. 5 (2005) p. 2174. 


\section{Figure legends}

Figure 1 A transmission electron micrograph of an as-processed nanoporous $\mathrm{Ni}$ specimen.

Figure 2 Scanning electron micrographs of (a) as-processed and (b-f) annealed nanoporous Ni specimens. Annealing temperatures were (b) 473 K, (c) 573 K, (d) 673 $\mathrm{K}$, (e) $773 \mathrm{~K}$ and (f) $873 \mathrm{~K}$.

Figure 3 X-ray diffraction patterns in diffraction angle ranges of (a) 30-90 and (b) 43-46 degrees for as-processed and annealed nanoporous Ni specimens.

Figure 4 Magnetization hysteresis loops measured at room temperature using vibrating sample magnetometer for (a) as-processed and (b-f) annealed nanoporous Ni specimens. Annealing temperatures were (b) 473 K, (c) 573 K, (d) 673 K, (e) 773 $\mathrm{K}$ and (f) $873 \mathrm{~K}$.

Figure 5 Variation in saturation magnetization $M_{\mathrm{s}}$ as function of (a) ligament length and (b) specific surface area for nanoporous Ni (open triangle). For reference, saturation magnetization of nanoparticle Ni (solid triangle, from ref. 2) is superimposed in (b).

Figure 6 Energy-dispersive X-ray (EDX) spectrum for as-processed nanoporous $\mathrm{Ni}$ specimen. 

KYOTO UNIVERSTTY

,

1

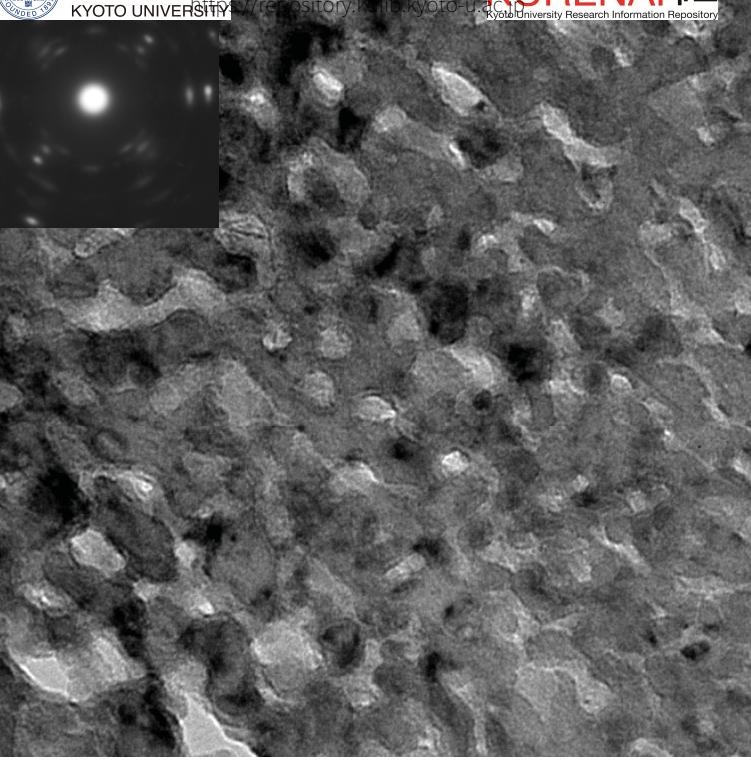

Figure 1 


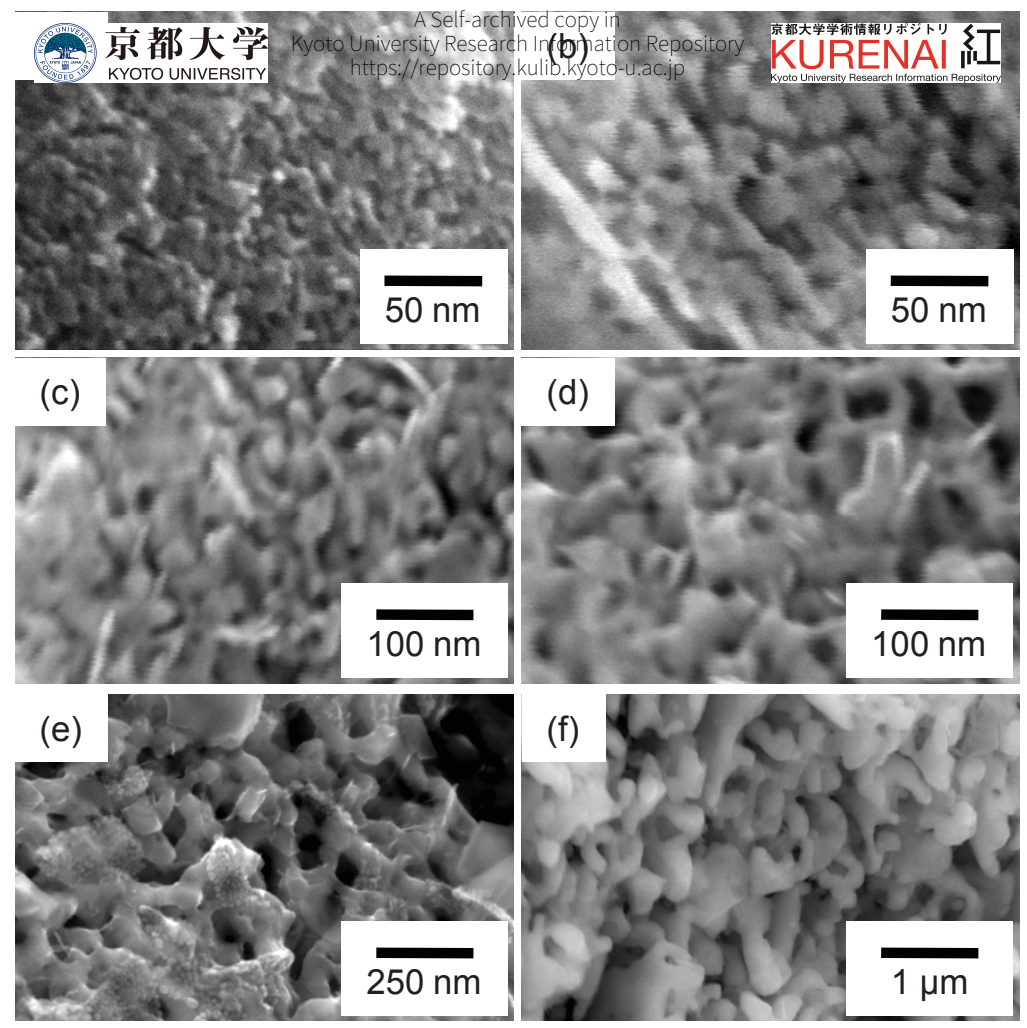



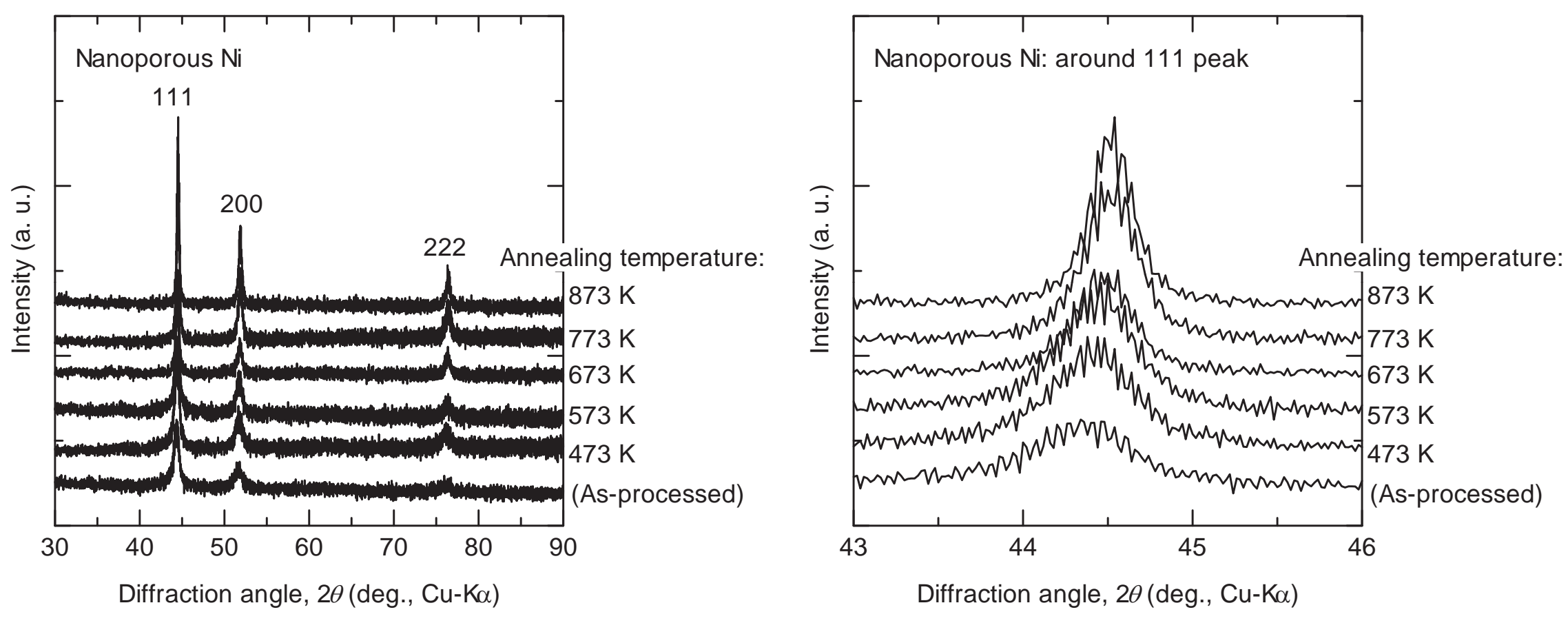

Diffraction angle, $2 \theta$ (deg., Cu-Ka)

Diffraction angle, $2 \theta$ (deg., Cu-K $\alpha$ ) 
A京都大学
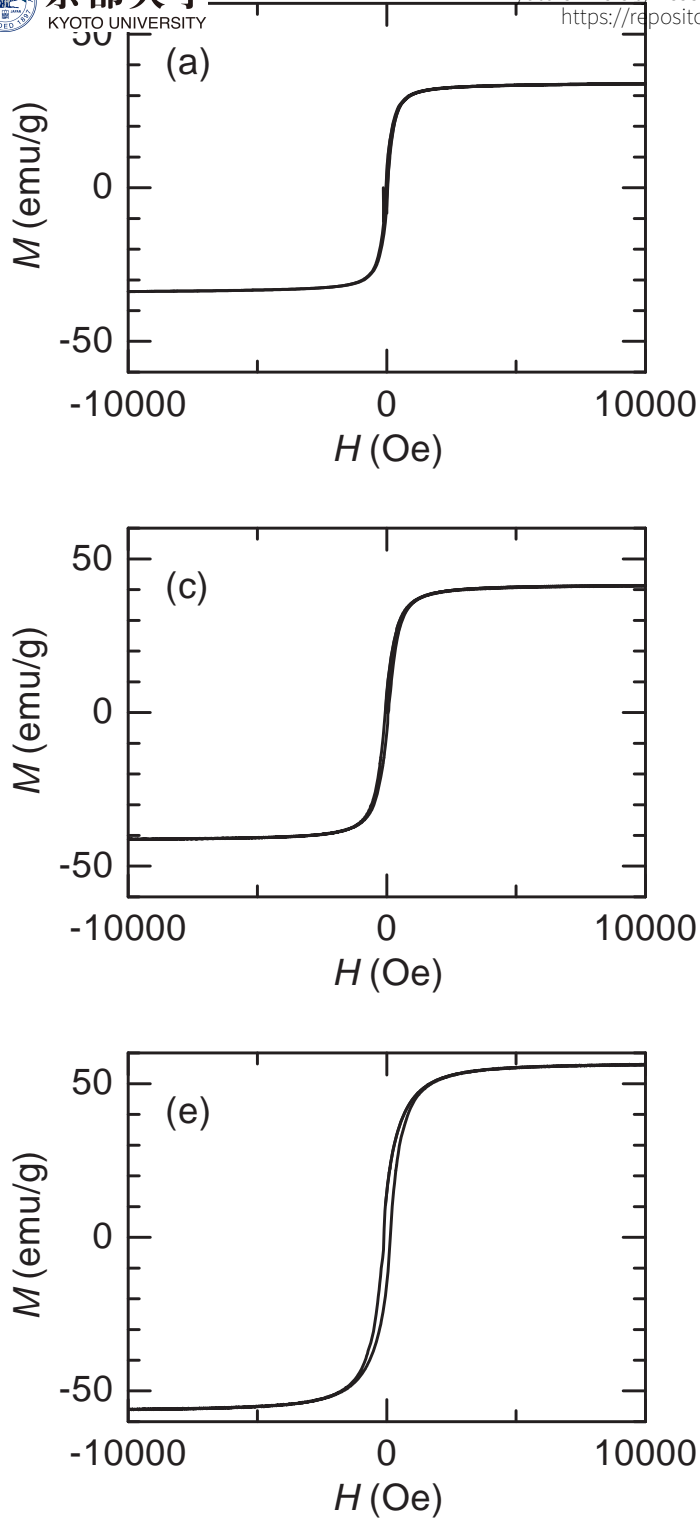
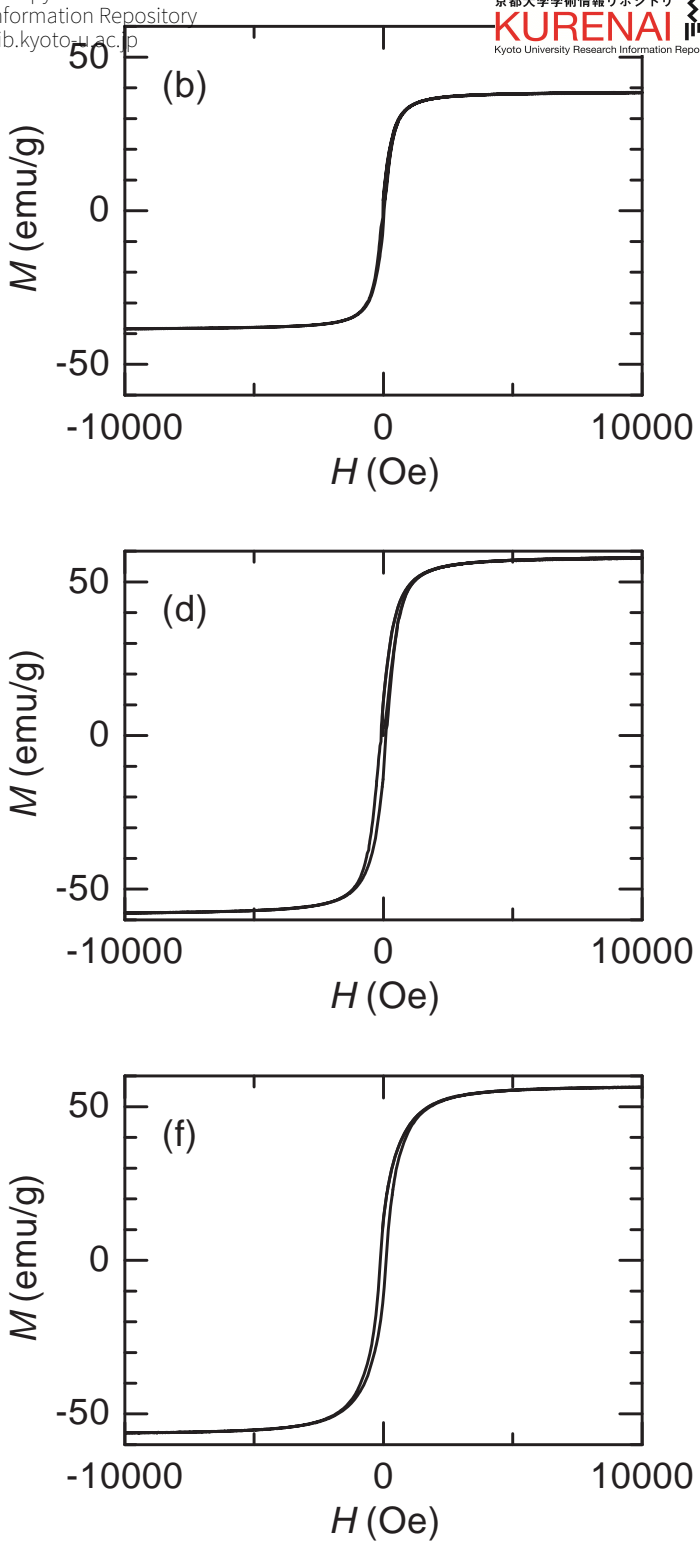

Figure 4 

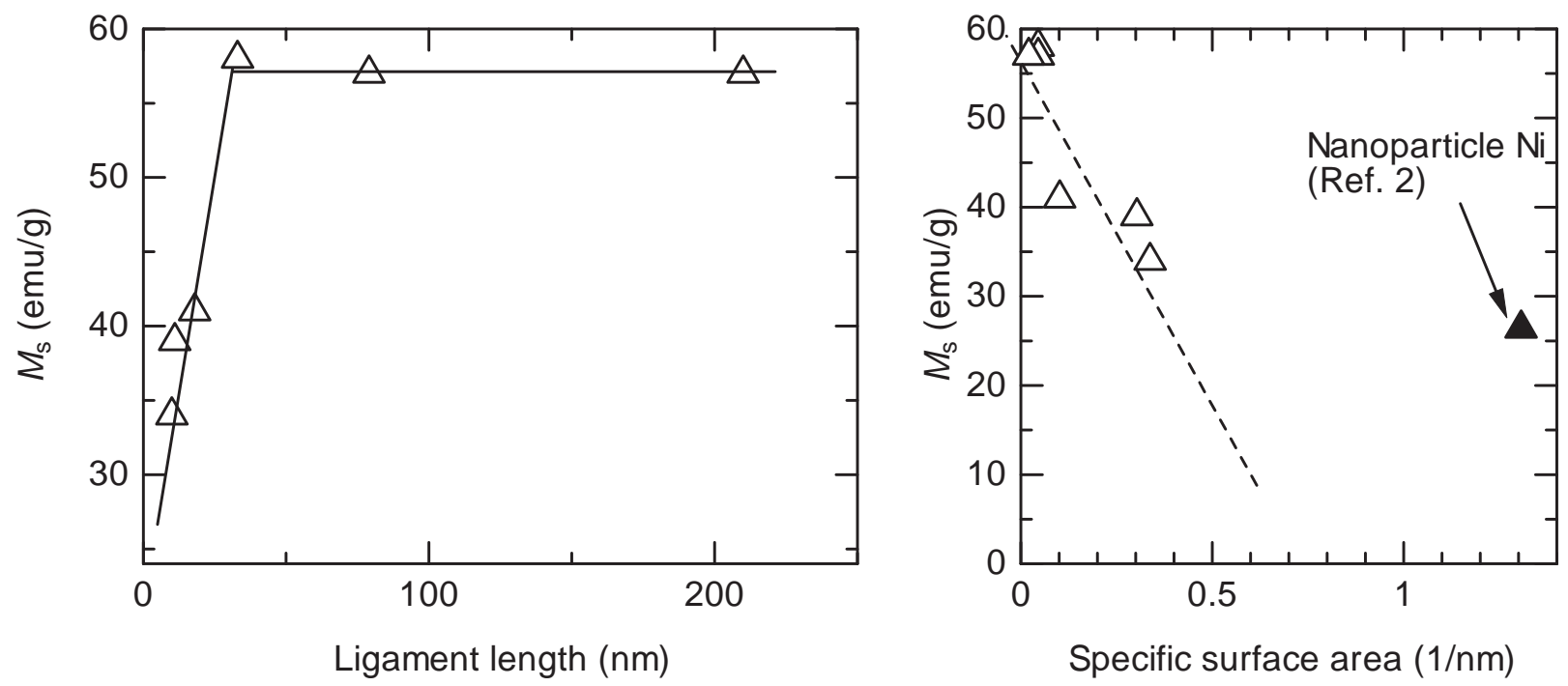
EDX spectrum

Nanoporous Ni, as-processed

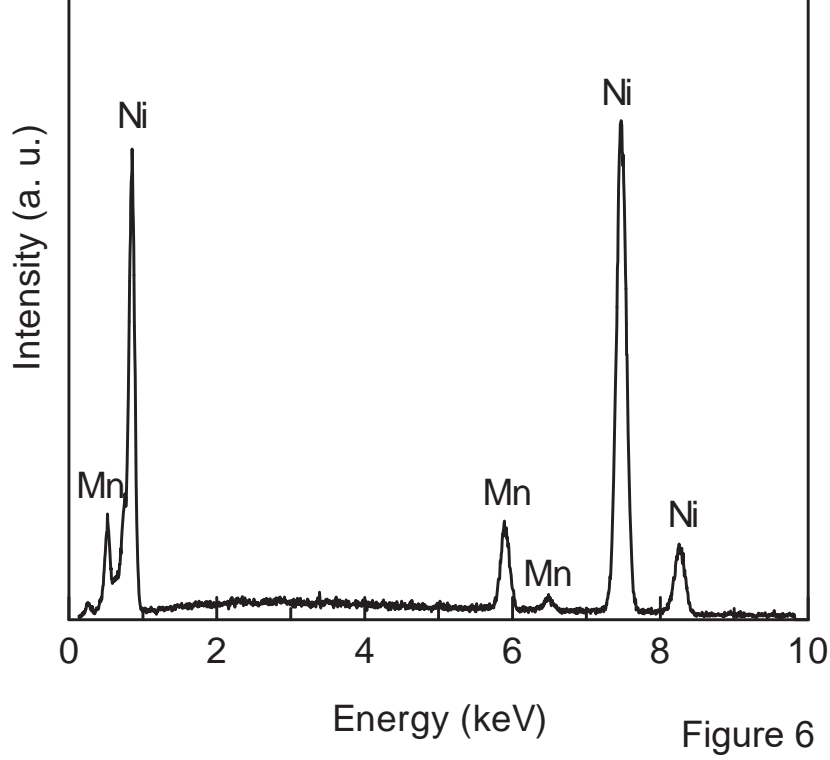

